\title{
Modeling Flood Risk for an Urban CBD Using AHP and GIS
}

\author{
Generino P. Siddayao, Sony E. Valdez, and Proceso L. Fernandez
}

\begin{abstract}
The Central Business District (CBD) of a city is the activity center of the city, typically locating the main commercial and cultural establishments, as well as acting as the center point of the city's transportation network. Flood risk assessment for a CBD is crucial for proper city planning and maintenance.

In this study, we model the flood risk for the CBD of Tuguegarao City, which is located in northern Philippines. To accomplish this, we identified important flood-related factors whose data are either easily available or may be collected through some automated process that we developed. We then surveyed experts to gather their estimation of the importance of the identified factors, and then used the AHP to determine the consistency of the expert judgments as well as the relative weights of each factor. These factor weights from the AHP were applied to the gathered data, and a Quantum GIS software tool was used for visualization, producing a geo-hazard map that is color-coded representing 5 levels of estimated flood risks.

Using such a GIS weighted overlay analysis map as guide, the city and municipal councils, planning agencies and other stakeholders can act to prepare for potential flooding or, better yet, proactively promote appropriate land-use policy that will minimize threat to lives due to flooding.
\end{abstract}

Index Terms - Analytic hierarchy process (AHP), decision support system, geographic information system, urban flooding.

\section{INTRODUCTION}

\section{A. Background}

Floods are one of the most widespread and savage of natural disasters. A flood is defined as the over-flowing by water of the normal confines of a stream or other body of water, or the accumulation of water by drainage over areas that are not normally submerged [1].

The most severe impacts of a flood are most likely to occur in urban areas where people, resources, and infrastructure are concentrated. In some urban areas, small streams can rise quickly after heavy rain due to higher generated run-off and less concentration time. Changes in the urban area and in the rain intensity produce higher flows that exceed the capacity of small culverts under roads. Although adequate when designed, the capacity of these culverts become inadequate over some time and thereby cause overflows onto the roads,

Manuscript received May 5, 2014; revised July 24, 2014

G. P. Siddayao is with the Cagayan State University-College of Information and Computing Sciences, Tuguegarao City, Philippines 3500 (e-mail: genersiddayao@gmail.com).

S. E. Valdez is with the Agoo Computer College, Agoo, La Union, Philippines (e-mail: shunyvaldez@gmail.com).

Proceso L. Fernandez is with the Ateneo de Manila University, Quezon City, Philippines (e-mail: pfernandez@ateneo.edu). creating new water paths and ultimately flood the built up areas. Moreover, in developing countries, the inadequate quality and maintenance of the drainage channels, and the build up of debris and even solid waste disposed into such drainage systems further aggravate the situation [1].

Flooding can result not only in costly damage to property, but can also pose a risk to life and livelihood. The occurrence of flood affects not only the city's inhabitants but also its industries and commerce, and may even lower the potential for investment [2].

In this study, we focus our flood risk modeling on an urban Central Business District (CBD). CBDs are activity centers for public offices, education, transportation, culture, sports, recreation, public health, product distribution and supply. CBD size, road and drainage structure influence the design and resulting performance of optimal land and network resource allocation strategies among urban zones. Fig. 1 shows a typical city with concentric city Ring Road network with the Central Business District as the core and center of community and commercial activities, while the Outer Ring road city limits are the location of major residential zones [3].

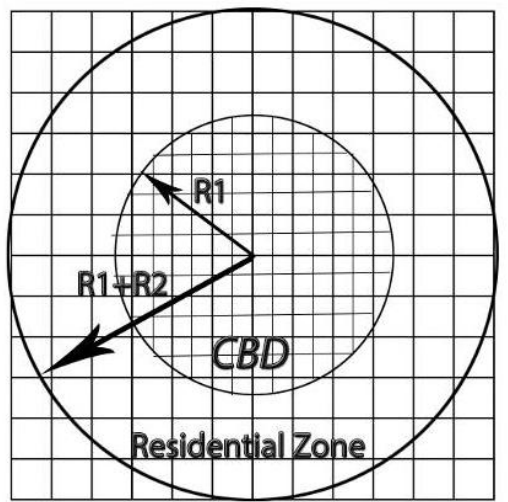

Fig. 1. Urban CBD with concentric inner city Ring road network [3].

This study explores how the Analytic Hierarchy Process (AHP) can be combined with spatial modeling for urban CBD flood risk assessment. A system is developed that integrates these, and then the system is applied to the Central Business District in City of Tuguegarao, an urban flood-prone area in southern Cagayan province which is located in the northern Philippines.

\section{B. Preliminary}

\section{1) How AHP works}

The AHP is a powerful tool that was introduced and developed by Saaty [4] in 1980. It is often used for decision making, and is based on a quantitative assessment of the various factors and alternatives being considered. The general flow of the AHP scheme is summarized in Fig. 2. 


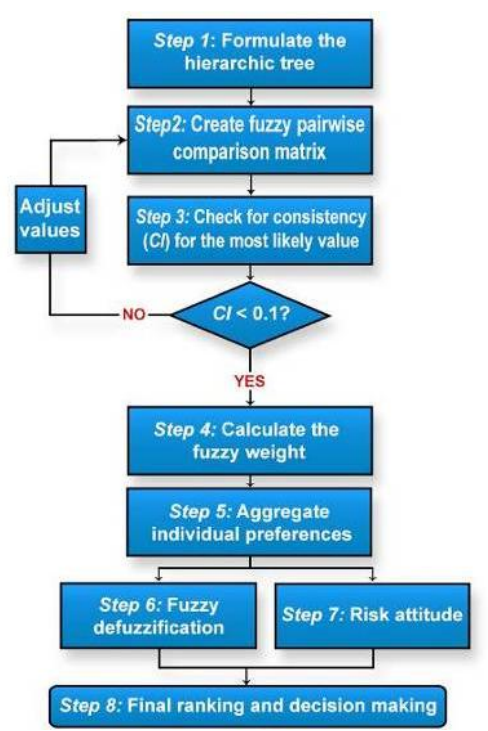

Fig. 2. Analytic hierarchy process (AHP) scheme [5].

In AHP, the decision making process starts with dividing the problem into issues, which may optionally be divided further to form a hierarchy of issues. These issues are those that are to be considered in tackling the problem. Such a hierarchical ordering often helps to simplify the problem and bring it to a condition which is more easily understood [6]. As illustrated in Fig. 3, a goal for some decision may be divided into several criteria, and in each criterion there may be multiple options or alternatives (represented by various $A_{i}$ 's). The final decision is arrived at after quantitatively analyzing the various alternatives and considering the criteria set in evaluating the quality of the decision.

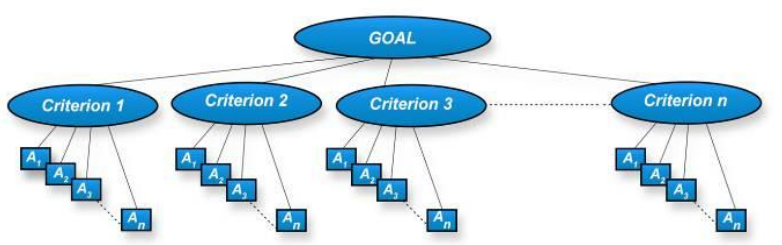

Fig. 3. Hierarchical tree structure of the AHP [6].

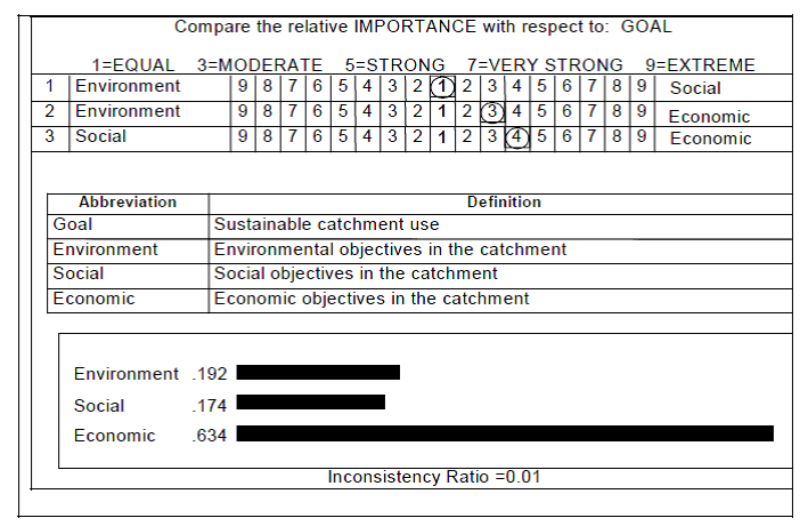

Fig. 4. Sample questionnaire of preferences at given objectives [7].

To be able to come up with such a quantitative assessment of any possible decision based on the given alternatives, the weights of the elements in each level of the hierarchy are estimated. These weights represent the relative importance of the elements in the achievement of the overall goal. For this purpose Saaty [4] developed the Pair-wise Comparison Method (PCM).

In PCM, each pair of elements under the same criterion is considered, and the relative importance of these two elements is established. This is typically done through a questionnaire. An example is provided in Fig. 4, where the relative intensity of importance of each of the Disaster Criteria, based on the expert's judgment and perception, is surveyed and an individual expert assessment is shown. In this example, the economic objective is appraised by the respondent to be 3 times as important as the environmental objective and 4 times as important as the social objective; the environmental and social objectives are considered equally important.

Aggregating the assessments of an individual respondent for all pairs generates Pair-wise Comparison matrix, whose general form is given below.

$$
A=\left[r_{i j}\right]=\left[\begin{array}{cccc}
1 & r_{12} & \cdots & r_{1 j} \\
1 / r_{12} & 1 & \cdots & r_{2 j} \\
\vdots & \vdots & \ddots & \vdots \\
1 / r_{1 j} & 1 / r_{2 j} & \cdots & 1
\end{array}\right]
$$

The elements of this matrix are the pair-wise (or mutual) importance ratios between the elements. That is, if $r_{i j}=k$, then element $A_{i}$ is considered to be $k$ times as important as $A_{i}$. Note that this also implies that $r_{i j}=1 / k$, and hence $r_{i j}=1 / r_{j i}$ for all pairs of elements. Furthermore, all the diagonal elements are 1 since an element is always equally important to itself. The values of this matrix provide the basis of how well every criterion serves and how important each is in reaching the final goal.

It is important to note, however, that people's preference systems are sometimes inconsistent, and that re-interview would not necessarily remove this problem, although it would provide the opportunity to probe particular tradeoffs contributing to the inconsistency [7]. A metric is usually employed to determine the consistency of the results.

\section{2) Consistency ratio in $A H P$}

In practice, it is unrealistic to expect the decision-makers to provide pair-wise comparison matrices which are perfectly consistent, especially in cases where there are sufficiently large numbers of alternatives. Expressing the real feelings of the decision makers involves some fuzziness. Such fuzziness, even in expert judgment, generally leads to matrices that are not quite consistent. However some matrices might violate consistency very slightly by only two or three elements while others may have values that cannot even be called close to consistent [6]. The measure of how far a matrix is from consistency may be determined by computing the Consistency Ratio (C.R.). This value is obtained by calculating the matrix product of the pair-wise comparison matrix and the weight vectors, and then adding all elements of the resulting vector. After that, a Consistency Index (C.I.) is computed using the following formula:

$$
\text { C.I. }=\frac{\lambda_{\max }-n}{n-1}
$$

where $n$ is the number of criteria and $\lambda_{\max }$ is the biggest eigenvalue [8]. To determine if the comparisons are consistent or not, the Consistency Ratio (C.R.) is calculated using the formula: 


$$
\text { C.R. }=\frac{\text { C.I. }}{\text { R.I. }}
$$

where R.I. is the Random Inconsistency index that is dependent on the sample size (refer to Table I). A reasonable level of consistency in the pair-wise comparisons is assumed if $C . R .<0.10$, while C.R. $\geq 0.10$ indicates inconsistent judgments.

TABLE I: RANDOM CONSISTENCY INDEX (R.I.) FOR $N=1,2 \ldots 8$ (ADAPTED FROM SAATY [4])

\begin{tabular}{ccccccccc}
\hline \hline $\mathrm{N}$ & 1 & 2 & 3 & 4 & 5 & 6 & 7 & 8 \\
\hline R.I. & 0.00 & 0.00 & 0.58 & 0.90 & 1.12 & 1.24 & 1.32 & 1.41 \\
\hline \hline
\end{tabular}

\section{RELATED LITERATURE}

AHP Applied to Urban Flood risk assessment

A dramatic increase in natural disasters attributed to climate change and the resulting damage is a global phenomenon, and is no exception in the Republic of Korea. For example, Seoul, its capital, received an enormously large amount of rain, $259.5 \mathrm{~mm}$, on September 21, 2010, which led to the flooding of the Sejong-no district. This incidence was an opportunity to draw public attention to the seriousness of climate change and for the authorities concerned to take action against those kinds of disasters. The damage from the flooding largely on the roads tarnished the Country's reputation because it suggested an inability to cope with extreme flooding events. Nevertheless, the district suffered very little damage. The flooding on the roads might have prevented the areas around the roads from being inundated and protected the government's important public tasks and private commercial functions [9].

TABLE II: THE RESUlTS OF ASSESSMENT FOR POSSIBLE STORM WATER DETENTION BASINS FLOOD MITIGATION [9]

\begin{tabular}{|c|c|c|c|c|c|}
\hline Categories & Ranking & $\%$ & Detailed Types & Ranking & $\%$ \\
\hline \multirow{3}{*}{ Transportation } & \multirow{3}{*}{1} & \multirow{3}{*}{20} & Local streets & 1 & 40 \\
\hline & & & Parking spaces & 2 & 34 \\
\hline & & & Bus terminals & 3 & 26 \\
\hline \multirow{3}{*}{ Public/ Education } & \multirow{3}{*}{1} & \multirow{3}{*}{20} & Schools & 1 & 45 \\
\hline & & & Universities & 2 & 29 \\
\hline & & & $\begin{array}{c}\text { Government } \\
\text { offices }\end{array}$ & 3 & 26 \\
\hline \multirow{3}{*}{ Spatial } & \multirow{3}{*}{3} & \multirow{3}{*}{19} & Urban parks & 1 & 40 \\
\hline & & & Squares/Plazas & 2 & 33 \\
\hline & & & Amusement Parks & 3 & 27 \\
\hline \multirow{2}{*}{$\begin{array}{c}\text { Culture and } \\
\text { sport/recreation }\end{array}$} & \multirow{2}{*}{4} & \multirow{2}{*}{14} & Sport facilities & 1 & 54 \\
\hline & & & Cultural facilities & 2 & 46 \\
\hline \multirow{3}{*}{ Public Health } & \multirow{3}{*}{4} & \multirow{3}{*}{14} & Medical centers & 1 & 42 \\
\hline & & & Cemeteries & 2 & 30 \\
\hline & & & Crematories & 3 & 28 \\
\hline \multirow{2}{*}{$\begin{array}{l}\text { Distribution and } \\
\text { supply }\end{array}$} & \multirow[t]{2}{*}{6} & \multirow[t]{2}{*}{12} & $\begin{array}{c}\text { Distribution } \\
\text { Centers }\end{array}$ & 1 & 53 \\
\hline & & & Markets & 2 & 47 \\
\hline
\end{tabular}

Analytical results show that 1) there is a consensus on using transportation and public/education infrastructure as a counter measure against extreme flooding; 2) local streets and schools, more specifically, are believed to be suitable for flood-related hazard mitigation; 3) some professional groups seem to be more or less reluctant to use spatial infrastructure including urban parks and squares (plazas) as storm water detention basins. Given that roads tend to take up a significant portion of urban surface, they have great potential to detain rainwater temporarily as related construction technique develops further. Of course, some roads for people's escape and emergency access for cars should be secured in advance.

Based on the six major categories and the 16 detailed types, the AHP method has been used to assess their appropriateness as being used as counter measure against extreme urban flooding. Table II shows the results of the AHP appropriateness assessment.

\section{CONCEPTUAL FRAMEWORK}

Fig. 5 shows how to produce a DSS and Geo-hazard map. All the Boolean algebra operations (e.g., intersection, union, negation, etc.) can be easily extended to fuzzy set operations. Therefore, if we can find a scheme to represent the spatial data from a fuzzy set perspective, then all the Boolean logic-based operations in GIS should also be extendible to fuzzy logic operations, which will lead to fuzzy cartographic modeling. Combining fuzzy set theory with GIS modeling procedures not only endows the latter with the capability to deal with imprecision and vagueness, but also promotes further applications of fuzzy sets in the spatial decision making process [10].

\section{METHODOLOGY}

Fig. 6 shows the methodology used in this study which was used for urban flood prediction mapping [11]. Maps, table field surveys and Remote Sensing information are part of data gathering. These were then processed using AHP and statistical processes, to produce such outputs as Geohazard maps, reports and statistical graphs or tables [12].

\section{A. Data Collection}

The city of Tuguegarao is in the province of Cagayan, northern Philippines, with Latitude $17^{\circ} 33^{\prime} 37^{\prime}$ ' N, Longitude $121^{\circ} 42^{\prime} 54^{\prime \prime} \mathrm{E}$, and with a population of about 135,000 . It is not only the capital city of Cagayan Province, it is also the regional capital of Region 2 (Cagayan Valley) with numerous government offices, financial institutions, hospitals, universities, places of worship, sports and cultural facilities are located.

There are primarily two types of data sources of Tuguegarao City: (1) Graph Data: political administration area, topographic data, drainage, and pond and creeks map (2) Document Data: population and socio-economic statistics, Unfortunately, the data for Drainage Density is not complete in all urban CBD barangays, and would be included in future studies. Fig. 7 shows red broken lines on political boundary, yellow shade for road network and blue shade for the river for the City of Tuguegarao. The city has numerous low-lying perennial ponds and creeks, where flood waters settle; it has an existing urban drainage system. The Pinacanauan River 
intersects eastern city barangays, while the Cagayan River crosses some southern and western barangays. The above natural features in climate and terrain are the main factors for causing flood hazard in this studied area. Refer to Fig. 7 for some details.

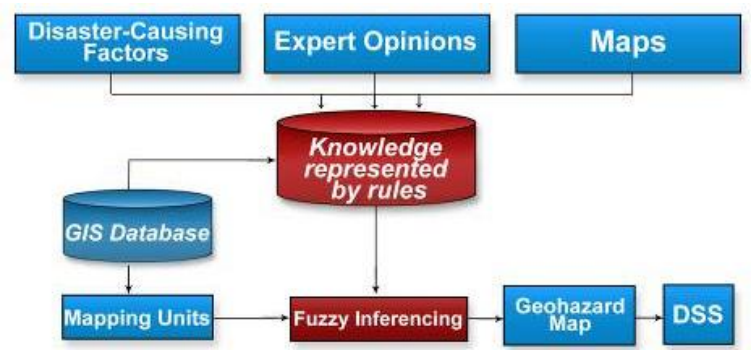

Fig. 5. Conceptual framework of the study.

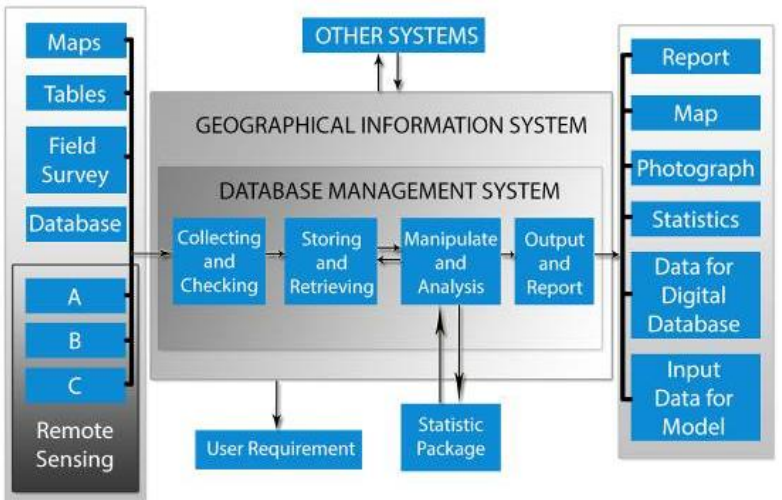

Fig. 6. Methodology integrating spatial analysis with AHP and remote sensing.

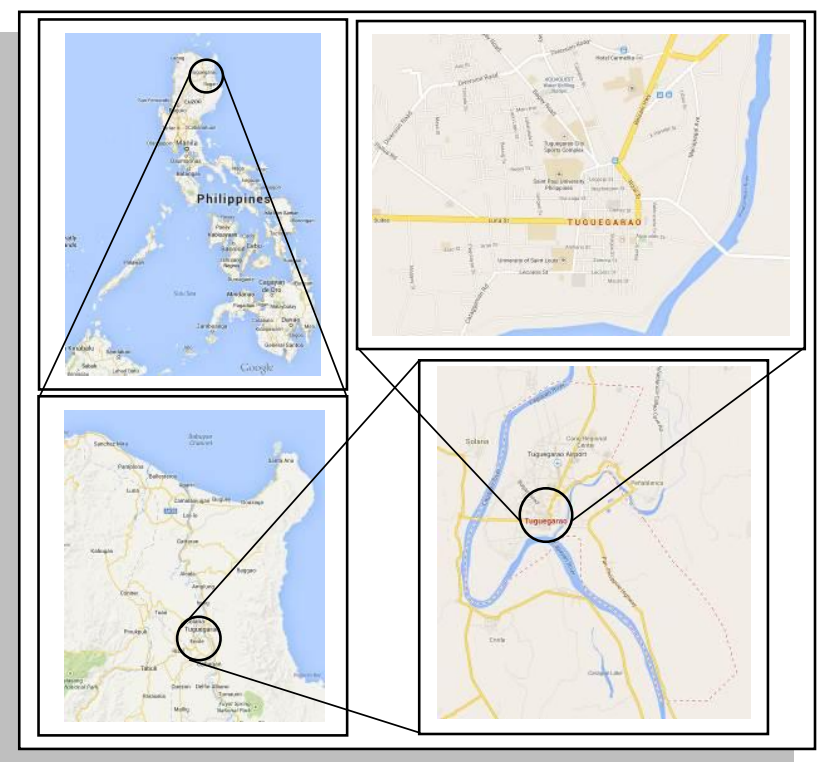

Fig. 7. Location of area of study.

For the Mapping and Table inputs, the CBD barangay maps were then subdivided into equidistant square grids for distance reference using a customized Python Application Programming Interface (API) on Google Maps. Vertical elevation intersections and horizontal boundaries of river banks, creeks and ponds were identified and marked for analytical measurement. The population density of each CBD barangay was gathered thereafter, tabulated and classified as shown in Table IV.

For the AHP Expert Judgment portion, a survey Questionnaire was floated to the different Tuguegarao residents and Offices like City Planning, Engineering, Management Information System, Administrator, Agriculture and Health. The data for AHP was gathered, analyzed and tabulated as in Table V, to calculate the weight of each disaster criteria from F1 to F4.

\begin{tabular}{ll}
\multicolumn{2}{c}{ TABLE III: DEFINING THE DISASTER CRITERIA } \\
\hline \hline Disaster Criteria (DC) & \multicolumn{1}{c}{ Description } \\
\hline Population Density (F1) & $\begin{array}{l}\text { The number of people per unit area, for } \\
\text { a given site. This is given in units of } \\
\text { people per square kilometer. }\end{array}$
\end{tabular}

Distance from Riverbank (F2)

Site Elevation (F3)

Distance from Ponds and Creeks (F4)
How near or far (in kilometers) a given site is from the nearest Riverbank.

How high or low a given site is. This is given in units of meters above sea bed reference level of Google Map.

How near or far (in kilometers) a given site is from the nearest Pond or Creek

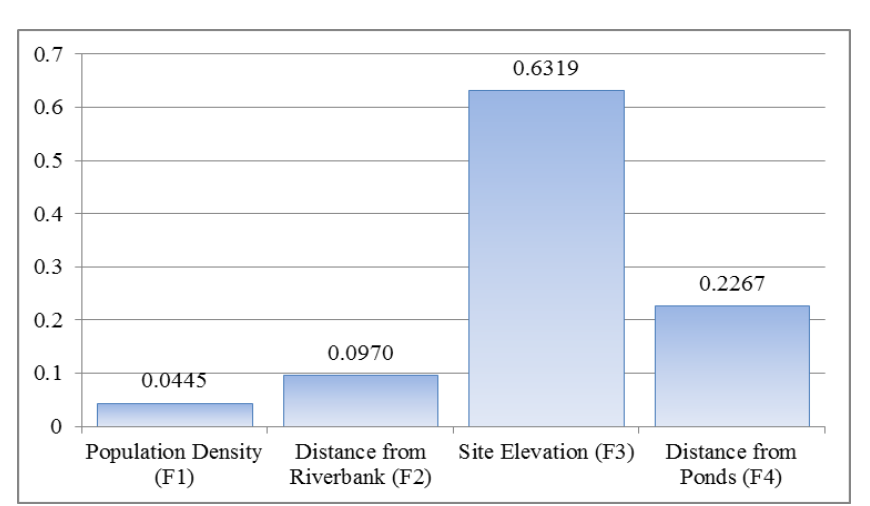

Fig. 8. Normalized weight of each disaster criteria.

TABLE IV: BASELINE SCALED DATA OF VARIOUS DISASTER-CAUSING

\begin{tabular}{c|c|c|c|c}
\hline $\begin{array}{c}\text { Geo-Hazard } \\
\text { Classification }\end{array}$ & $\begin{array}{c}\text { Population } \\
\text { Density } \\
\left(\text { people/ } / \mathrm{km}^{2}\right)\end{array}$ & $\begin{array}{c}\text { Distance } \\
\text { from } \\
\text { Riverbank } \\
(\mathrm{km})\end{array}$ & $\begin{array}{c}\text { Site } \\
\text { Elevation } \\
(\mathrm{m})\end{array}$ & $\begin{array}{c}\text { Distance } \\
\text { from Ponds } \\
\text { and Creeks } \\
(\mathrm{km})\end{array}$ \\
\hline $\begin{array}{c}\text { Very Low } \\
\text { Risk }\end{array}$ & $18-36$ & $1.31-1.64$ & $29.50-32.50$ & $1.459-1.824$ \\
$\begin{array}{c}\text { Low Risk } \\
\text { Moderate } \\
\text { Risk }\end{array}$ & $36-55$ & $0.99-1.31$ & $26.60-29.50$ & $1.095-1.459$ \\
$\begin{array}{c}\text { High Risk } \\
\text { Very High }\end{array}$ & $55-74$ & $0.67-0.99$ & $23.69-26.60$ & $0.731-1.095$ \\
Risk & $92-111$ & $0.02-0.35$ & $17.89-20.79$ & $0.002-0.366$ \\
\hline \hline
\end{tabular}

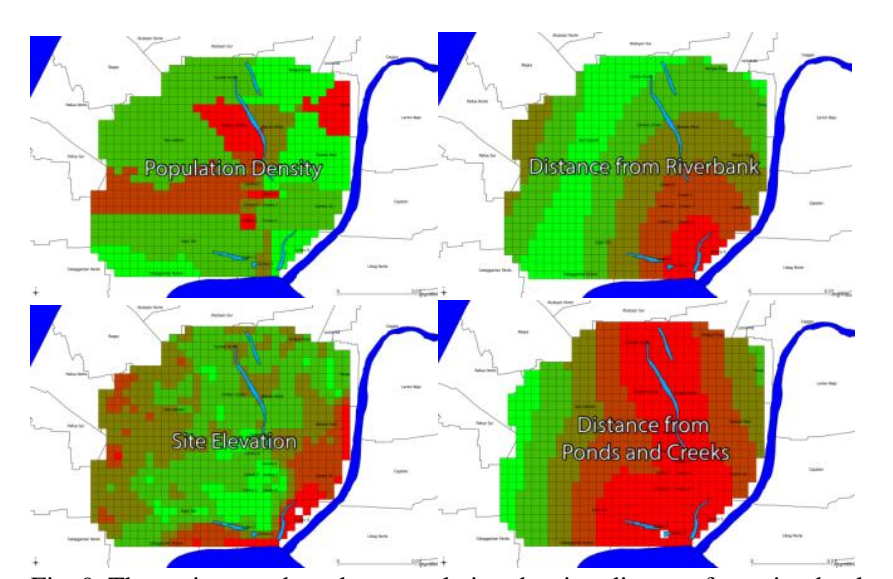

Fig. 9. Thematic maps based on population density, distance from riverbank, site elevation and distance from ponds and creeks using quantum GIS. 


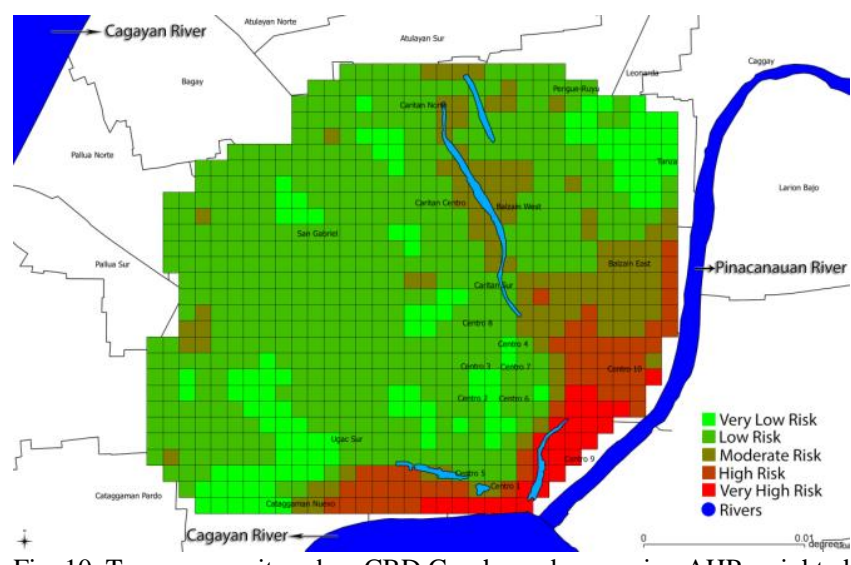

Fig. 10. Tuguegarao city urban CBD Geo-hazard map using AHP weighted overlay analysis and remote sensing on existing quantum GIS.

\section{RESUlTS AND ANALYSIS}

\section{A. Computation of Pair-wise Comparison Matrix and Consistency}

Pair-wise comparison matrix is created by assigning weights by experts. The weights are further evaluated in finding alternatives and estimating associated absolute numbers from 1 to 9 in fundamental scales of the AHP [13]. These weights can be computed automatically in IDRISI (Eastman 1995), Microsoft Excel as well as in Expert Choice (Expert Choice Quick Start Guide, 2000-2004) software called Multi- Criteria Decision Analysis (MCDA) tool. Hence, the results of relative weights of $\mathrm{F} 1=$ Population Density, F2 = Distance from Riverbank, F3 = Site Elevation and F4 = Distance from Ponds and Creeks are shown in Table $\mathrm{V}$. The pair-wise comparison matrix is calculated herein using the Microsoft Excel in determining priority weights for this study [14].

TABLE V: CRiteria Weighting CALCUlation FOR FloOd SUSCEPTIBLE AREAS

\begin{tabular}{c|cccc|cccc|c}
\hline \hline \multicolumn{9}{c|}{ STEP I } & \multicolumn{5}{c|}{ STEP II } & STEP III \\
\hline & F1 & F2 & F3 & F4 & F1 & F2 & F3 & F4 & Weight \\
\hline F1 & 1.00 & 0.33 & 0.11 & 0.14 & 0.05 & 0.02 & 0.07 & 0.02 & 0.0445 \\
\hline F2 & 3.00 & 1.00 & 0.14 & 0.33 & 0.15 & 0.08 & 0.09 & 0.05 & 0.0970 \\
\hline F3 & 9.00 & 7.00 & 1.00 & 5.00 & 0.45 & 0.61 & 0.68 & 0.77 & 0.6319 \\
\hline F4 & 7.00 & 3.00 & 0.20 & 1.00 & 0.35 & 0.26 & 0.13 & 0.15 & 0.2267 \\
\hline Sum & 20.00 & 11.33 & 1.45 & 6.47 & 1.00 & 1.00 & 1.00 & 1.00 & 1.0000 \\
\hline \hline
\end{tabular}

TABLE VI: CONSISTENCY RATIO (CR) CALCULATION

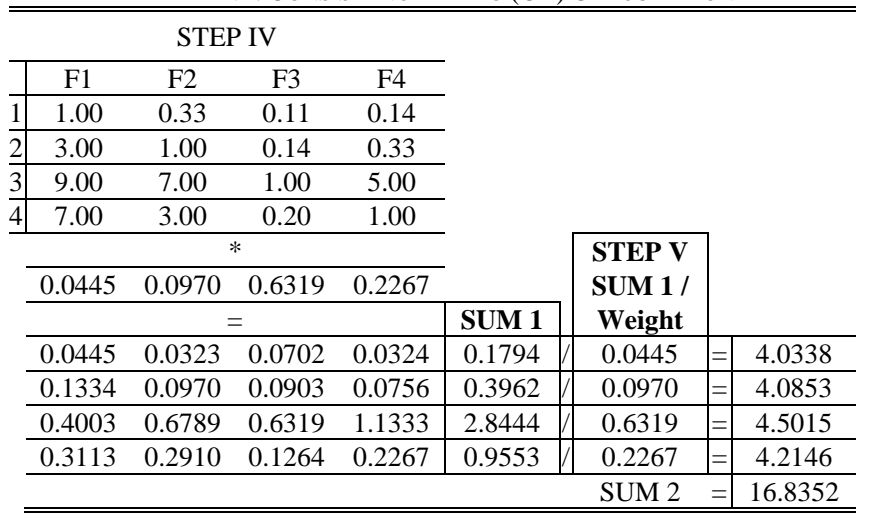

\section{STEP VI:}

R.I. $=0.90$ at $n=4$ in Table II, adapted from Saaty [4], Lawal et al. [14], Cabala [15]:

$$
\begin{gathered}
\lambda_{\max }=\frac{1}{n_{i}} \sum_{i=1}^{n} \frac{{ }^{c}}{w_{i}} \\
\lambda_{\max }=\frac{1}{4}(16.8352)=4.2088
\end{gathered}
$$

STEP VII: From (2)

$$
\text { C.I. }=\frac{\lambda_{\max }-n}{n-1}=\frac{4.2088-4}{4-1}=0.0696
$$

STEP VIII: From (3)

$$
\text { C.R. }=\frac{\text { C.I. }}{\text { R.I. }}=\frac{0.0696}{0.90}=0.0773
$$

TABLE VII: SUMMARY OF VALUES

\begin{tabular}{cc}
\hline \hline Parameters & Values \\
\hline$\lambda_{\max }$ & 4.2088 \\
C.I. & 0.0696 \\
R.I. & 0.90 \\
C.R. & $0.0773(\leq 0.1)$ REASONABLE \\
\hline \hline
\end{tabular}

The main visualization output of this study is shown in Fig. 10. This was generated after calculating the criteria weights using AHP and integrating these weights with some GIS-based steps that include layer overlays, raster conversion, and some clipping. The AHP computation results reveal that the Site Elevation (F3) at $63.19 \%$ is assessed by experts to be the largest contributing factor for flooding, followed by Distance from Ponds (F4) at $22.67 \%$, Distance from Riverbank (F2) at $9.70 \%$ and Population Density (F1) at $4.45 \%$ (see Fig. 8). The consistency as measured in the pair-wise comparisons of C.R. $=0.0773$ (value $<0.10$ ) indicates that the basis expert judgment is reasonably consistent.

For the location-based data, the Site Elevation (F3), Distance from Ponds (F4) and Distance from Riverbank (F2) were taken from Google Map's available Application Programming Interface (API) using customized grids and a developed Python program using the existing Quantum GIS maps. Finally, a Geo-hazard map was generated from the integration of criteria weights from AHP with the criteria maps into the GIS software. The map presents a rank of highest and lowest suitability areas. The geo-hazard classification is divided into five classes: Very Low Risk, Low Risk, Moderate Risk, High Risk and Very High Risk (see Fig. 10).

\section{CONCLUSIONS}

In this study, AHP is combined with GIS to come up with a tool for evaluating flood risks in the CBD areas in Tuguegarao City. Such tool was developed after gathering topological information about the city and also reliable (C.R. $<0.10$ ) expert criteria assessment for flood risks, and then applying fuzzy logic techniques based on AHP to an open source Quantum GIS software.

The developed tool will be a very valuable resource for consulting, planning agencies and local governments in 
managing risk, land-use zoning, damage estimates, land tax valuation, life and property insurance claim validation, good governance, lifeline emergency services and remediation efforts to mitigate risks. Moreover, the technique applied in this study can easily be extended to other areas, where other factors may be considered, depending on the availability of data.

\section{RECOMMENDATIONS}

Drainage Density and Rainfall Intensity should be included in future studies to complete the urban CBD flood hazard study, as data becomes available. The knowledge domain of hydrologists, meteorologists, geologists and actuarial science experts is much needed for activities in Natural Hazard Research. Getting such experts to help makes sure that inputs, processes and outputs are scientific, reliable and sustainable. Local councils, consultants, planning agencies and stakeholders can use these models so that they can come up with land-use policies related to natural hazard risk that fit within the time-frame of natural processes. It is hoped that this study would provide a scalable AHP in GIS Disaster decision support system that can be used in diverse environment with their own disaster-related factors, for coastal, mountainous, metropolitan, suburban areas et al.

\section{ACKNOWLEDGMENT}

This work was supported in part by the Commission on Higher Education of the Philippines and the University of Cordilleras, Baguio City, Philippines.

The authors wish to express their gratitude to Honorable Mayor Jefferson P. Soriano of Tuguegarao City, Cagayan, Philippines, his administrative staff, City Council and colleagues at Cagayan State University for their collaboration in this research.

\section{REFERENCES}

[1] O. Ozcan and N. Musaoglu, "Vulnerability analysis of floods in urban areas using remote sensing and GIS," Remote Sensing for Science, Education, and Natural and Cultural Heritage, p. 4, 2010.

[2] G. Kandilioti and C. Makropoulos, "Preliminary flood risk assessment: the case of Athens," Nat Hazards, vol. 61, pp. 441-468, DOI: 10.1007/s11069-011-9930-5, 2012.

[3] T. Tsekeris and N. Geroliminis, "City size, network structure and traffic congestion," Journal of Urban Economics, vol. 1, no. 14, p. 3, 2013.

[4] T. L. Saaty, The Analytic Hierarchy Process: Planning, Priority Setting, Resource Allocation, New York, NY: Mcgraw-Hill, 1980.

[5] L. Diaz-Balteiro and C. Romero, "Modeling timber harvest scheduling problems with multiple criteria: an application in Spain," Forest Science, vol. 44, no. 1, pp. 47-57, 1997.

[6] M. Kordi, "Comparison of fuzzy and crisp analytic hierarchy process (AHP) methods for spatial multicriteria decision analysis in GIS," Department of Technology and Built Environment at University of Gavle, pp. 7-9, September 2008.

[7] S. Harrison and M. Qureshi, "Application of the analytic hierarchy process to riparian revegetation policy options," Smallscale Forest Economics, Management and Policy, vol. 2, no. 3, pp. 441-458, 2003.

[8] J. Malczewski, GIS and Multiple-Criteria Decision Analysis, New York: John Wiley and Son, 1999.
[9] T. J. Kwon, "Urban infrastructure suitable for flood hazard mitigation," in Proc. IAIA13 Conference Proceedings' Impact Assessment the Next Generation 33rd Annual Meeting of the International Association for Impact Assessment, pp. 1-4, 2013.

[10] T. T. Nguyen, "Fuzzy GIS approach to land capability and suitability analysis," 2013.

[11] M. Z. Sarker and A. Sivertun, "GIS and RS combined analysis for flood prediction mapping - A case study of dhaka city corporation, Bangladesh," International Journal of Environmental Protection, vol. 1 , no. 3, 2011.

[12] A. B. Yaakup, F. Johar, and I. M. Yusof, "Development control system and GIS for local authority in Malaysia: A case at Kuala Lumpur City Hall," in Proc. the 5th International Conference in Computers in Urban Planning and Urban Management, Bombay, India, 1997.

[13] T. L. Saaty, "Decision making with the analytic hierarchy process," International Journal Services Sciences, vol. 1, no. 1, 2008.

[14] D. Lawal, A. Matori, A. Hashim, K. Yusof, and I. Chandio, "Detecting flood susceptible areas using GIS-based analytic hierarchy process," International Conference on Future Environment and Energy, vol. 28, pp. 3-4, 2012.

[15] P. Cabala, "Using the analytic hierarchy process in evaluating decision alternatives," Operations Research and Decisions, vol. 1, pp. 5-23, 2010 .

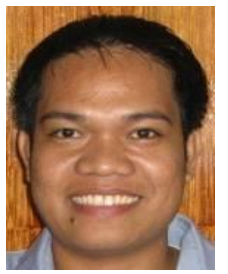

Generino P. Siddayao was born in Tuguegarao City, Philippines, on April 21, 1980. He received his B.S. and M.S. degrees in information technology from Saint Paul University Philippines (SPUP) at Tuguegarao City, Philippines in 2001 and 2004, respectively; He takes interest in systems analysis and programming for various enterprise applications.

He has worked in the academe for over 12 years and he is currently an assistant professor of Cagayan State University at Tuguegarao City, Philippines. Current his research interests include artificial intelligence applications in geographical information systems for risk assessment and resource management. Prof. Siddayao is a member of Philippine Society of Information Technology Educators (PSITE).

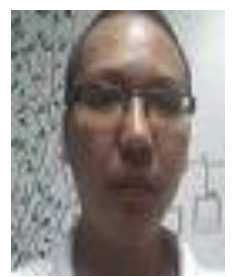

Sony E. Valdez was born in Agoo, La Union, Philippines, on March 15, 1984. He received his B.S. degree in computer science from Agoo Computer College, La Union, Philippines in 2004, and his M.S. degree in Information Technology from the University of the Cordilleras in 2010 . He is currently studying for his doctorate in information technology at the University of the Cordilleras in the Philippines. He

takes interest in the field of artificial intelligence, video games, pokemon and programming.

He has worked in the programming industry for over 11 years and he has been teaching masters and college IT students for the past 3 years. His current research involves developing an artificial intelligence to play in competitive games such as Rock-Paper-Scissors. He is looking to extend the AI research to include boxing games, Pokemans and Street Fighting.

Prof. Valdez is the current president of Python. PH, Inc, a non-profit organization with the goal of spreading the programming language Python to the country. He is a member of the International Game Developer's Association (Manila Chapter) since 2009.

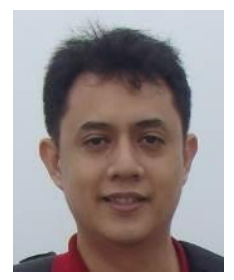

Proceso L. Fernandez was born in Quezon City, Philippines, on June 19, 1972. He received the B.S. M.S. and Ph.D. degrees in computer science from the Ateneo de Manila University, Quezon City, Philippines, in 1994, 2001 and 2009, respectively. He is currently an associate professor at the same university. He has been a visiting researcher at the Nara Institute of Science and Technology, Nara, Japan, since 2011. He has also been a visiting professor at the Ateneo de Davao University, Davao, Philippines and at the University of the Cordilleras, Baguio, Philippines. He is currently a member of the Computing Society of the Philippines. 